\title{
Cost-Effective Solution of Input Voltage Stabilizer of Auxiliary Drive Converter for Traction Vehicles
}

\author{
Jan Stepanek ${ }^{1}$, Martin Jara ${ }^{1}$, Pavel Drabek ${ }^{1}$ \\ ${ }^{1}$ Regional Innovation Centre for Electrical Engineering, University of West Bohemia, \\ Univerzitni 8, Pilsen 306 14, Czech Republic \\ quido@rice.zcu.cz
}

\begin{abstract}
This paper describes a prospective design concept of a hard switching input voltage stabilizer for the auxiliary drives converters of dc catenary fed light traction vehicles. Auxiliary drives are mostly dedicated to generate standard power grid that supplies various on-board equipment and charging on-board batteries. The input voltage stabilizer (IVS) is the first input block of auxiliary drives. This block defines the voltage level of the consequent $\mathrm{dc} / \mathrm{dc}$ isolated converter (IC). The main aim of this paper is to present the reader with the design of a low-cost variant of the voltage stabilizer. The described input voltage stabilizer is designed as a buck (step-down) or boost (step-up) converter, operating with an input catenary voltage range of 400 (VDC) to $950 \mathrm{VDC}$. The new fast, discrete IGBT $\mathrm{H3}$ transistors and $\mathrm{SiC}$ diodes allow switching frequency from $20 \mathrm{kHz}$ to $30 \mathrm{kHz}$ in a hard switching mode with power rated up to $22 \mathrm{~kW}$.
\end{abstract}

Index Terms-DC-DC power conversion, converters, switching frequency, hard switching, auxiliary drives.

\section{INTRODUCTION}

This research has been motivated by our industrial partner with the aim of developing a new generation of electric equipment for light traction vehicles (mainly mass transport vehicles like trolley buses and trams). One part of light rail vehicles' electric equipment is the traction converter for auxiliary drives which consists of input voltage stabilizer (IVS) and the dc/dc isolated converter, which operates at high switching frequencies and under hard switching conditions. The auxiliary drives are an integrated part of light traction vehicles. They are mostly used for generating a standard power grid which supplies various on-board equipment and charges on-board batteries. The auxiliary drives are designed while taking into consideration the voltage range of the DC catenary. In our case, the dc catenary voltage range of light traction vehicles may vary between $400 \mathrm{VDC}-950 \mathrm{VDC}$ for rated catenary voltage $600 \mathrm{VDC}$ and $750 \mathrm{VDC}$.

In Fig. 1 a block diagram describes one of the commonly used topologies of the light rail vehicles' electrical

Manuscript received January 8, 2015; accepted April 8, 2015.

This research has been supported by the European Regional Development Fund and Ministry of Education, Youth and Sports of the Czech Republic under project No. CZ.1.05/2.1.00/03.0094: Regional Innovation Centre for Electrical Engineering (RICE) and project No. SGS2015-038 equipment, including auxiliary drives [1]. For simplicity's sake, we omit the charger branch [2], [3] as a part of auxiliary drives in the traction drive structure. The main branch includes the input filter IF $\left(\mathrm{L}_{\mathrm{F}}, \mathrm{C}_{\mathrm{F}}\right)$ and the main traction converter (MTC) feeding the traction motor (TM). The IF is generally a supply source for the whole electrical equipment of light traction vehicle [4], [5] and its voltage level varies widely according to catenary line. The major electrical device (from the rated power point of view) is MTC plus TM. The auxiliary drives are the secondary electrical branch with lower power. It is nevertheless of great importance for the vehicle's safety. The input part of the auxiliary drives is the input voltage stabilizer (IVS) with LC filter $\left(\mathrm{L}_{\mathrm{DC}}, \mathrm{C}_{\mathrm{DC}}\right)$ as a source for the following $\mathrm{dc} / \mathrm{dc}$ isolated converter (IC). This block presents a simple topology providing a galvanic isolation between the catenary and auxiliary drives' potentials and, importantly, it protects the passengers inside the vehicle. The IC consists of input single-phase inverter (e.g. full or half bridge transistor topology), a high frequency transformer (HFT) [6]-[10] and an output rectifier (diode or the active one). The IVS has a significant impact on the design of $\mathrm{L}_{\mathrm{DC}}, \mathrm{C}_{\mathrm{DC}}$ filter (values, size and price). A prospective design concept of input voltage stabilizer is the main contribution of this paper.

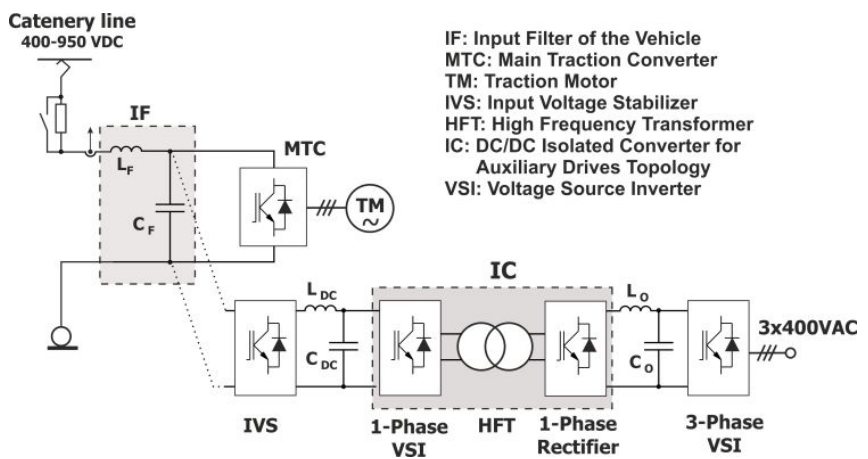

Fig. 1. Design concept of an auxiliary power supply.

\section{AUXILIARY DRIVES CONVERTER TOPOLOGY}

In general, the auxiliary drive topology can be divided into two groups due to connection to input filter IF:

1. The isolated DC/DC converter IC is connected to IF through the input voltage stabilizer IVS.

2. The isolated DC/DC converter IC is directly connected 
to IF and provides stabilizing function as well.

The first group uses the IVS to stabilise the input catenary voltage (may vary $400 \mathrm{VDC}-950 \mathrm{VDC}$ ) to define the voltage level (lower or higher than input range) and to supply IC. Selected basic topologies are shown in Fig. 2 and Fig. 3.

The second group doesn't use IVS to supply IC and the input part of IC is directly connected to catenary voltage. Selected basic topologies are shown in Fig. 4 and Fig. 5.

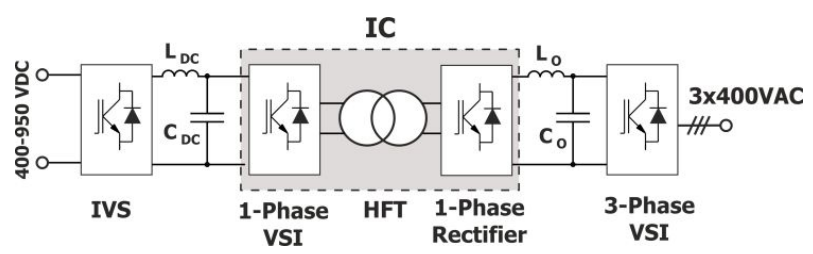

Fig. 2. Standard auxiliary drives topology with IVS.

The block diagram in Fig. 2 describes the standard topology of auxiliary drives. The input voltage stabilizer is designed for connection to the dc catenary voltage range (400 VDC - $950 \mathrm{VDC}$ ) and therefore the $1700 \mathrm{~V}$ device is used. The BUCK converter [11] mode is usually used to stabilise input voltage to e.g. 380 VDC (can also be BOOST converter [11] mode to stabilise to e.g. $1200 \mathrm{VDC}$ ). The main drawback is using a $1700 \mathrm{~V}$ semiconductor device which causes several demerits such as lower switching frequencies, higher switching losses, a higher price, etc.

As well as the buck converter mode, it is also possible to use the BOOST converter mode, e.g. to stabilise the input catenary voltage to $1200 \mathrm{VDC}$. However, because of the properties of the $1700 \mathrm{~V}$ semiconductor device it is not commonly used.

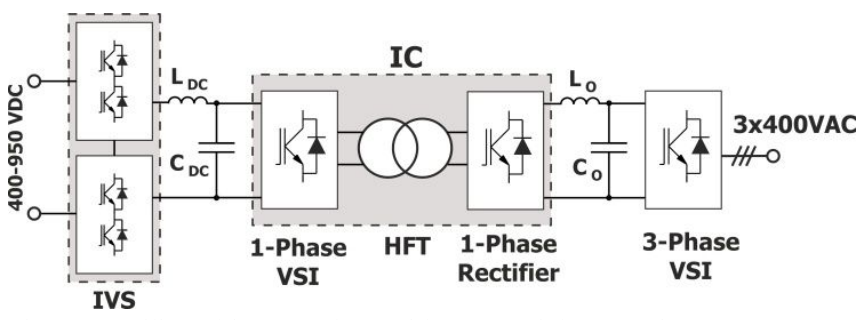

Fig. 3. Auxiliary drives topology with IVS (serial connection).

Figure 3 presents the block diagram of the auxiliary drives' topology with the IVS as a serial connection of two input BUCK/BOOST converters. The serial connection enables the use of the $1200 \mathrm{~V}$ semiconductor devices, which bring several merits such as higher switching frequencies, lower switching losses, a lower price etc. However, as a drawback we have to mention the higher number of semiconductor devices. In comparison with the topology in Fig. 2, the $1200 \mathrm{~V}$ semiconductor devices allow higher switching frequencies which enable significant elimination of size and value of passive components $\mathrm{L}_{\mathrm{CD}}$ and $\mathrm{C}_{\mathrm{DC}}$.

The second group presents a topology where the IC is directly connected to IF (catenary voltage) without IVS. In this case we must pay the utmost attention to the voltage dimension of the input part of IC and we have to use $1700 \mathrm{~V}$ devices or a serial connection of $1200 \mathrm{~V}$ devices. The current standard topology uses a switching frequency of around tens of $\mathrm{kHz}$ of HFT, and this demand excludes $1700 \mathrm{~V}$ devices.
A serial connection of $1200 \mathrm{~V}$ devices or converter sections enable higher switching frequencies as well, however due to an input voltage range of $400 \mathrm{VDC}-$ 950 VDC and HFT ratio, it is necessary to consider the output rectifier dimension (in some cases the $1700 \mathrm{~V}$ devices are necessary).

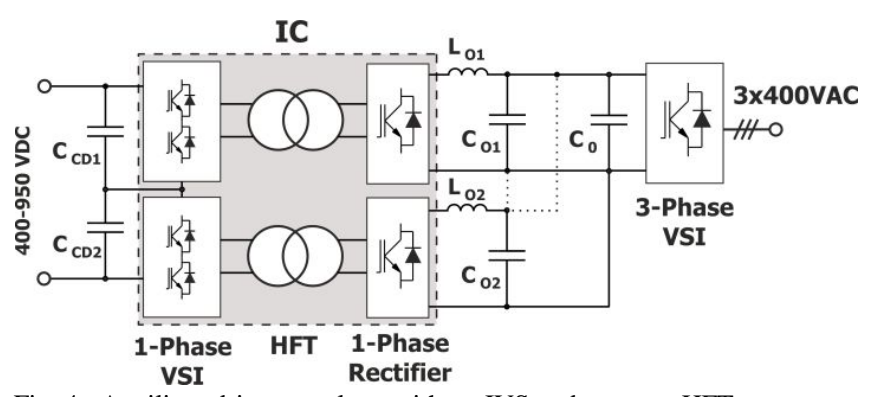

Fig. 4. Auxiliary drives topology without IVS and separate HFT.

In Fig. 4 the input part the IC consists of two serial single phase inverters which are connected to two separate HFTs and two rectifiers on the output side. The secondary rectifiers can be connected in serial or parallel combination (dashed lines in Fig. 4). Each variant presents some merits and demerits: 1) serial connection $(+1200 \mathrm{~V}$ devices, voltage balancing), 2) parallel connection (+ easy voltage control, $-1700 \mathrm{~V}$ rectifier devices).

Similar topology is shown in Fig. 5 where two serial single-phase inverters feed one common HFT with dual input windings and a single output winding.

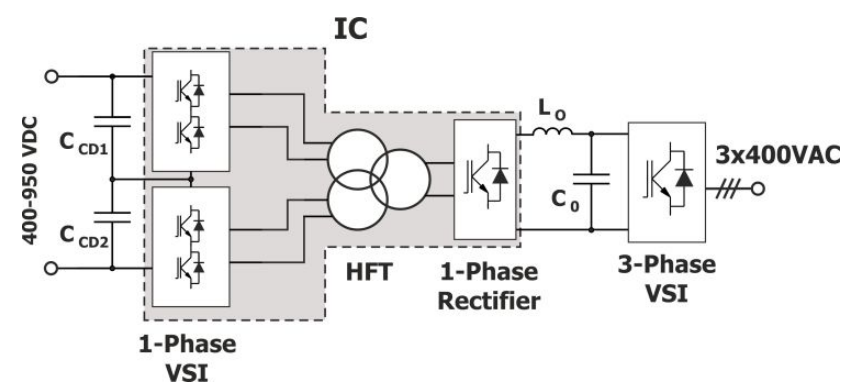

Fig. 5. Auxiliary drives topology without IVS and one common HFT.

This topology employs the effect of common magnetic flux of HFT, which naturally balances input filter capacitors $\mathrm{C}_{\mathrm{DC} 1}$ and $\mathrm{C}_{\mathrm{DC} 2}$. Moreover, a single HFT output ensures appropriate voltage range and enables using $1200 \mathrm{~V}$ devices in the output rectifier.

\section{THE DEVElopMent OF A NEW CONVERTER CONCEPT OF INPUT VOLTAGE STABILIZER}

Following our industrial partner's demand for the development of a new generation of electric equipment for light traction vehicles, the converter concept of auxiliary drives was modified. The auxiliary drive converter is part of the traction vehicle's electric equipment. In present days there is a strong emphasis on placing all the electrical equipment on the top of the vehicle. Therefore the size and weight constraints become highly significant; furthering high efficiency, low price, reliability and life-time. Due to the typical industrial use in mass transport vehicles reliability and life-time should be the most important targets. However the price is also important for manufacturer in the competitive environment. 
The existing topology of auxiliary drive converter is based on the scheme in Fig. 2. As the main problem we can pinpoint the IVS based on $1700 \mathrm{~V}$ devices (single BUCK converter operating at $8 \mathrm{kHz}$ ) and IC structure using HFT at $50 \mathrm{kHz}$. The new converter concept of auxiliary drives is based on the scheme in Fig. 3 with emphasis on size, weight and price reduction (IVS operates at $30 \mathrm{kHz}$, IC using the HFT at $100 \mathrm{kHz}$, secondary rectifier only in diode version Fig. 6). This paper is focused on the new concept of input voltage stabilizer (IVS), therefore we will discuss only IVS in following text. The new concept of IC is not discussed in this paper.

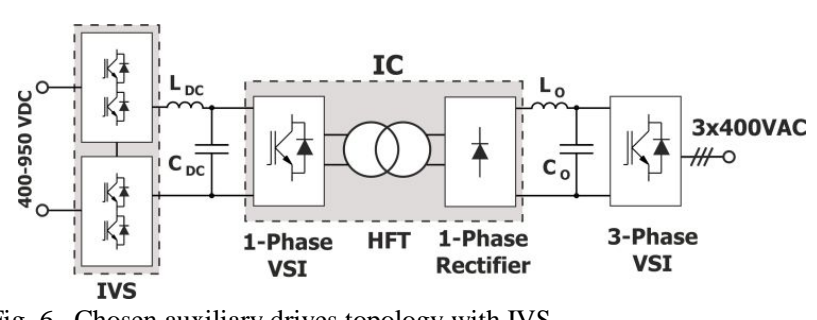

Fig. 6. Chosen auxiliary drives topology with IVS.

Input converter IVS (Fig. 6) based on serial combination of buck converters enables using $1200 \mathrm{~V}$ devices in discrete packages and under hard switching conditions (with regard to input voltage range we do not use soft switching conditions [3], [12], [13]). The IVS converter is supposed to stabilise input catenary voltage to e.g. $380 \mathrm{VDC}$ as a DC voltage level for the rest of the auxiliary drives converter structure.

The new concept of IVS (Fig. 6) is aiming to achieve size, weight and price reduction in comparison with the existing IVS concept (Fig. 2). The new concept of IVS is based on discrete TO247 devices (lower price) with an air cooling system and it operates at a $30 \mathrm{kHz}$ switching frequency (reduces passive components $\mathrm{L}_{\mathrm{DC}}$ and $\mathrm{C}_{\mathrm{DC}}$ ).

The equation (1) describes the dependency of IVS current ripple on the circuit parameters. It is evident that the appropriate value of IVS current ripple corresponds to switching frequency $f$ and inductance $\mathrm{L}_{\mathrm{DC}}$. Therefore for the identical current ripple and higher switching frequency we can use smaller value of inductance $\mathrm{L}_{\mathrm{DC}}$. Switching frequency increase from $8 \mathrm{kHz}$ to $30 \mathrm{kHz}$ allows inductance $\mathrm{L}_{\mathrm{DC}}$ significant reduction from $1,2 \mathrm{mH}$ to $0,3 \mathrm{mH}$ (Table I and Table II) while keeping the same current ripple. This reduction keep similar current stress and thus the voltage ripple on the output capacitor $C_{D C}$ under the same operating conditions

$$
\Delta i_{L}=\frac{U_{I N} T_{O N}}{L_{D C}}\left(1-\frac{T_{O N}}{T}\right)=\frac{U_{I N}}{f_{S W} L_{D C}} z(1-z),
$$

where $z=\frac{T_{O N}}{T_{S W}}, \quad f_{S W}=\frac{1}{T_{S W}}, \quad \mathrm{z}-$ duty cycle, $\mathrm{i}_{\mathrm{L}}-$ inductor current ripple, $U_{I N}$ - input voltage of IVS, $T_{O N}-$ ON time of IGBTs of IVS, $T_{S W}-$ switching period, $L_{D C}-$ IVS filter inductor, $f_{S W}-$ switching frequency.

The size, weight and price reductions are approximately summarized in following Table I and Table II. In the new concept of IVS we are considering a serial connection of 2 BUCK converters and each active switch as a parallel combination of 3 IGBTs for accurate current density (total number of 6 IGBTs and $6 \mathrm{SiC}$ diodes, both in discrete TO247 package).

\section{TABLE I. EXISTING IVS CONCEPT.}

\begin{tabular}{|c|c|c|}
\multicolumn{2}{c}{ TABLE I. EXISTING IVS CONCEPT. } \\
\begin{tabular}{|c|c|c|}
\hline Part & Parameters & $\begin{array}{c}\text { Approximate } \\
\text { price }\end{array}$ \\
\hline IGBT switch & $1700 \mathrm{~V}, 100 \mathrm{~A}, 8 \mathrm{kHz}$, module & $1 \times 235 \$$ \\
\hline Driver & $8 \mathrm{~A}, 50 \mathrm{kHz}, 1,7 \mathrm{kV}$ & $1 \times 195 \$$ \\
\hline $\mathrm{L}_{\mathrm{DC}}$ & $\begin{array}{c}1,2 \mathrm{mH}, 55 \mathrm{~A}, 8 \mathrm{kHz}, \\
0,15 \mathrm{~m} \times 0,15 \mathrm{~m} \times 0,15 \mathrm{~m}, 7 \mathrm{~kg}\end{array}$ & $314 \$$ \\
\hline Heatsink & $0,215 \mathrm{~m} \times 0,265 \mathrm{~m}, 4,5 \mathrm{~kg}$ & $78 \$$ \\
\hline
\end{tabular}
\end{tabular}

TABLE II. NEW IVS CONCEPT.

\begin{tabular}{|c|c|c|}
\multicolumn{3}{c|}{ TABLE II. NEW IVS CONCEPT. } \\
\hline Part & Parameters & $\begin{array}{c}\text { Approximate } \\
\text { price }\end{array}$ \\
\hline IGBT switch & $\begin{array}{c}1200 \mathrm{~V}, 40 \mathrm{~A}, 30 \mathrm{kHz}, \\
\text { discrete TO247 }\end{array}$ & $6 \times 7 \$$ \\
\hline Driver & $6 \mathrm{~A}, 50 \mathrm{kHz}, 1,2 \mathrm{kV}$ & $2 \times 125 \$$ \\
\hline SiC diode & $\begin{array}{c}1200 \mathrm{~V}, 2 * 10 \mathrm{~A}, \\
\text { discrete TO247 }\end{array}$ & $6 \times 19 \$$ \\
\hline $\mathrm{L}_{\mathrm{DC}}$ & $\begin{array}{c}0,3 \mathrm{mH}, 55 \mathrm{~A}, 30 \mathrm{kHz}, \\
0,1 \mathrm{~m} \times 0,1 \mathrm{~m} \times 0,1 \mathrm{~m}, 4 \mathrm{~kg}\end{array}$ & $235 \$$ \\
\hline Heatsink & $0,215 \mathrm{~m} \times 0,265 \mathrm{~m}, 4,5 \mathrm{~kg}$ & $78 \$$ \\
\hline
\end{tabular}

Comparing Table I and Table II we can conclude that the new IVS concept reduces the price by $13 \%$ (915 \$ of existing concept versus 805 \$ of new concept), the size by $7 \%\left(9 \mathrm{dm}^{3}\right.$ of existing concept versus $8.4 \mathrm{dm}^{3}$ of new concept) and finally the weight by $15 \%(16.5 \mathrm{~kg}$ of existing concept versus $14.1 \mathrm{~kg}$ of new concept).

The price reduction of $13 \%$ of the new concept is caused by cheaper discrete devices (including two drivers) and cheaper inductance $\mathrm{L}_{\mathrm{DC}}$. The size is very similar ( $7 \%$ reduction in size) and the decrease is mainly achieved by a smaller inductance $\mathrm{L}_{\mathrm{DC}}$ (the switching frequency is $4-$ times higher). Finally, the weight is reduced by $15 \%$ due to discrete devices and lighter inductance $\mathrm{L}_{\mathrm{DC}}$.

\section{HARDWARE PROTOTYPE}

Table III summarizes the basic application requirement for the designed IVS. There is a strong demand for the switching frequency to be well above the audible range. That suggests dominant switching loss related to the diode reverse recovery as well.

TABLE III. BASIC IVS PARAMETERS.

\begin{tabular}{|c|c|c|}
\hline Input voltage & $\mathrm{U}_{\text {in_min }}=400 \mathrm{VDC}$ & $\mathrm{U}_{\text {in_max }}=1000 \mathrm{VDC}$ \\
\hline Output voltage & \multicolumn{2}{|c|}{$\mathrm{U}_{\text {out_min }}=380 \mathrm{VDC}$} \\
\hline Output power & \multicolumn{2}{|c|}{$\mathrm{P}_{\max }=22 \mathrm{~kW}$} \\
\hline Current & \multicolumn{2}{|c|}{$\mathrm{I}_{\max }=58 \mathrm{~A}$} \\
\hline Switching frequency & \multicolumn{2}{|c|}{$\mathrm{f}_{\mathrm{sw} \_\max }=30 \mathrm{kHz}$} \\
\hline
\end{tabular}

The antiparallel combination of a SiC Schottky diode (the reason for using $\mathrm{SiC}$ instead of $\mathrm{Si}$ is described in [14]) IDW20S120 and high speed diode-less IGBT transistors IGW40N120H3 was chosen to overcome this drawback.

Another major concern was the generally poor thermal performance of the TO-247 package of these price effective components. With respect to the desired power output there were three transistors parallelly employed as a single switching cell in the converter.

As already mentioned, the selected topology (Fig. 7) consists of two series buck converters. The laboratory prototype was designed so that it could exhibit additional functionality such as bidirectional power flow or boost 
mode. That's why $S_{2}$ and $S_{4}$ are indicated in Fig. 7 as an active switch even though only $\mathrm{SiC}$ diodes are used in reality in the described buck operation (furthermore, $S_{1}$ and $\mathrm{S}_{3}$ will be the only IGBTs in the buck operation - therefore in Table II there are 6 pcs of IGBTs and SiC diodes. The component values are summarized in TABLE IV.

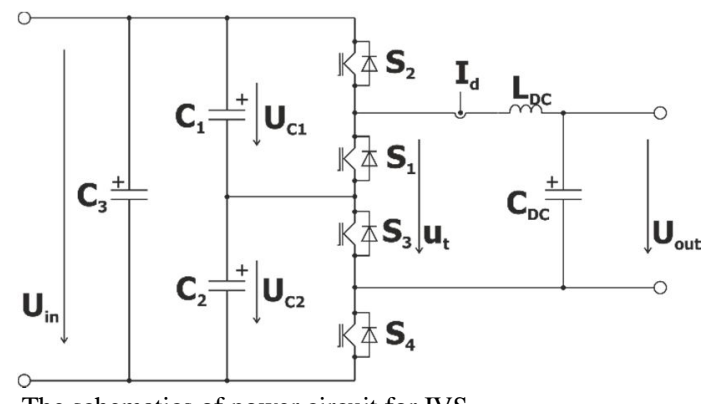

Fig. 7. The schematics of power circuit for IVS.

TABLE IV. CIRCUIT COMPONENTS VALUES.

\begin{tabular}{|c|c|}
\hline $\mathbf{C}_{\mathbf{3}}-$ Capacity of input filter & $1 \mathrm{mF}$ \\
\hline $\mathbf{C}_{\mathbf{1}}=\mathbf{C}_{\mathbf{2}}-$ Balancing capacitor & $470 \mu \mathrm{F}$ \\
\hline $\mathbf{L}_{\mathbf{0}}-$ Inductance of output filter & $900 \mu \mathrm{H}$ \\
\hline $\mathbf{C}_{\mathbf{0}}-$ Capacity of output filter & $500 \mu \mathrm{F}$ \\
\hline
\end{tabular}

The parallel combination of IGBTs and SiC diodes places demands on careful design of the power circuit as it may produce disruptive parasitic oscillations. In the laboratory prototype the single section was implemented as a three layer PCB with great emphasize on the sandwiches structure of power planes and matching gate circuits.

The 3D model of a single buck converter (IVS section) is shown on Fig. 8. and Fig. 9 depicts the hardware setup.

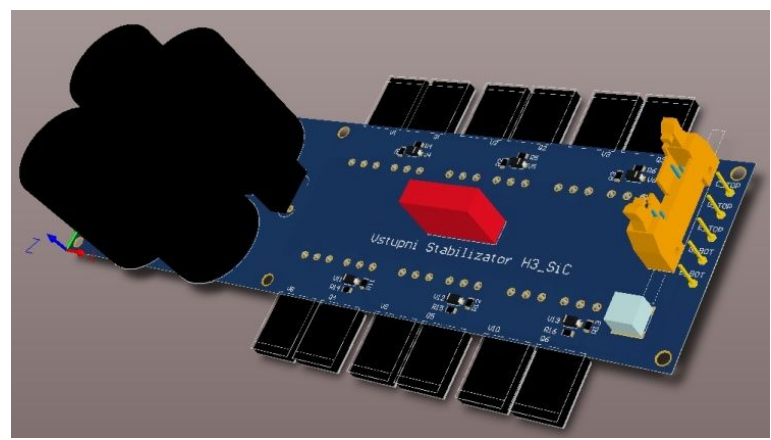

Fig. 8. 3D model of IVS single section.

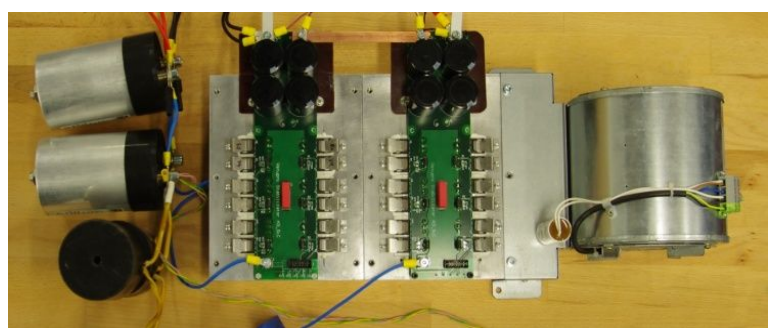

Fig. 9. Laboratory prototype of $22 \mathrm{~kW}$ IVS.

The control of the converter has to guarantee both correct output voltage value and even distribution of voltage levels imposed on both serially connected sections $\left(\mathrm{U}_{\mathrm{C} 1}\right.$ and $\left.\mathrm{U}_{\mathrm{C} 2}\right)$. The control scheme proposed for the converter is based on a well-known voltage control with an inner current loop formed by two cascaded PI type regulators. This regulator cascade, directly controlling one of the sections, is extended with a third PI type regulator. It inputs the converter section voltage difference and its output represents a difference in modulation signal for the sections. Once summed with the modulation signal provided by the cascade, it controls the second section. The variable length of the second section's PWM pulses with respect to the first one provides the voltage balancing capability while assuring the safe operation of $1200 \mathrm{~V}$ devices under high catenary voltage levels.

\section{MEASUREMENT RESUlts}

The IVS laboratory prototype performance was verified by a series of experiments in steady and transient states. The ability to properly balance the section voltages under various transient conditions was closely examined. In order to forcibly create severely unbalanced conditions one section was additionally loaded.

Steady state operations are depicted in Fig. 10 upon the $600 \mathrm{~V}$ input voltage. Converter start-up waveforms are presented in Fig. 11 (with forced imbalance - the voltage imbalance is made by external resistor) and Fig. 12 (without forced imbalance). The waveforms confirm proper function of balancing control algorithm of serial IVS converters.

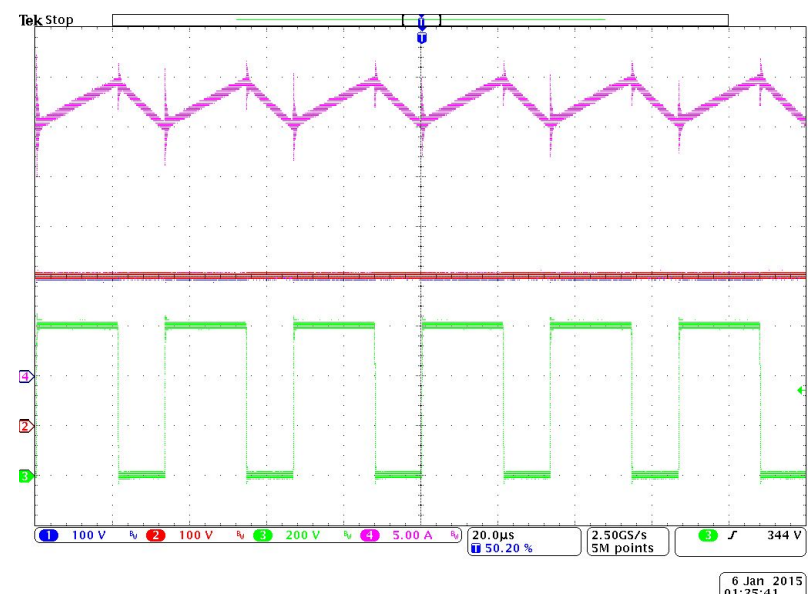

Fig. 10. Steady state conditions (Uin $=600 \mathrm{VDC}$, Pout $=10 \mathrm{~kW}$ ) Ch1 Uc1 $100 \mathrm{~V} / \mathrm{div}, \mathrm{Ch} 2$ - Uc2 $100 \mathrm{~V} / \mathrm{div}, \mathrm{Ch} 3$ - ut $200 \mathrm{~V} / \mathrm{div}, \mathrm{Ch} 4$ Id 5 A/div, time base 20 us/div.

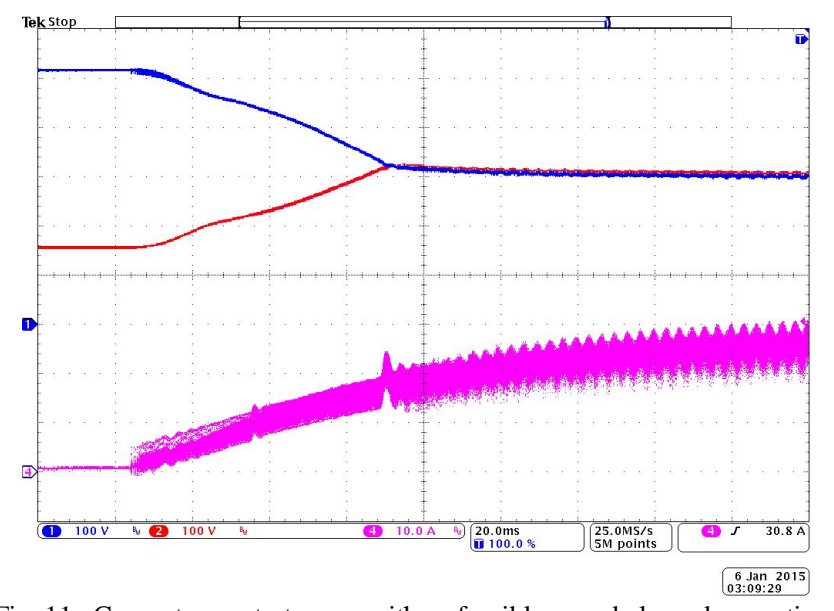

Fig. 11. Converter start-up with forcibly unbalanced sections $\left(\mathrm{U}_{\text {in }}=600 \mathrm{VDC}, \mathrm{P}_{\text {out }}=10 \mathrm{~kW}\right) \mathrm{Ch}_{1}-\mathrm{U}_{\mathrm{c} 1} 100 \mathrm{~V} / \mathrm{div}, \mathrm{Ch}_{2}-\mathrm{U}_{\mathrm{c} 2} 100 \mathrm{~V} / \mathrm{div}$, $\mathrm{Ch}_{4}-\mathrm{I}_{\mathrm{d}} 10 \mathrm{~A} / \mathrm{div}$, time base $20 \mathrm{~ms} / \mathrm{div}$.

There is a minor imbalance shown on the latter picture. It is caused by asymmetries of both sections involving $\mathrm{C}_{1}$ and $\mathrm{C}_{2}$ parameters, tiny gate pulse differences and other parasitic influences. It took approximately $80 \mathrm{~ms}$ until the regulator fully compensated the effect. 
No adverse conditions were found during other transient transients. These include abrupt dip of input voltage (Fig. 13) and load changes (Fig. 14).

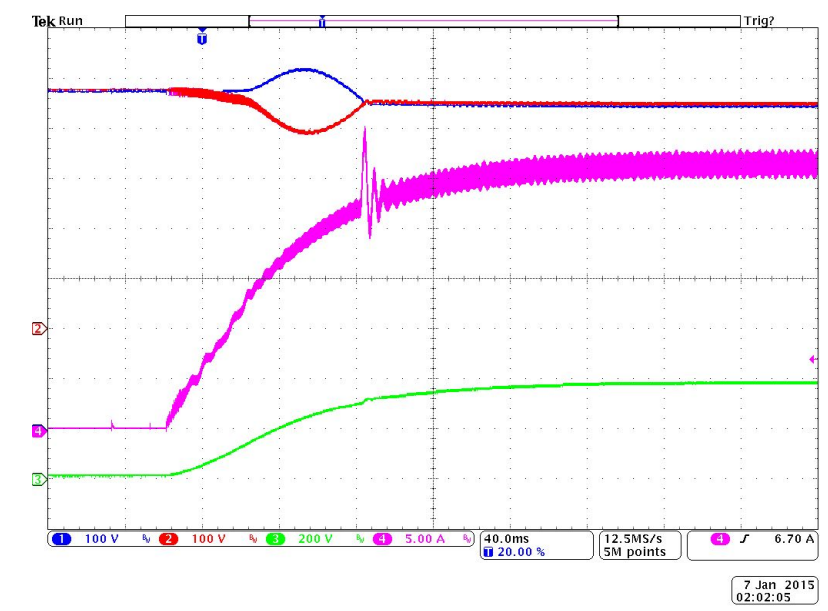

Fig. 12. Converter start-up without forcibly unbalanced sections $\left(\mathrm{U}_{\mathrm{in}}=600 \mathrm{VDC}, \mathrm{P}_{\text {out }}=10 \mathrm{~kW}\right), \mathrm{Ch} 1-\mathrm{U}_{\mathrm{c} 1} 100 \mathrm{~V} / \mathrm{div}, \mathrm{Ch} 2-\mathrm{U}_{\mathrm{c} 2} 100 \mathrm{~V} / \mathrm{div}$, $\mathrm{Ch} 3-\mathrm{u}_{\text {out }} 200 \mathrm{~V} / \mathrm{div}, \mathrm{Ch} 4-\mathrm{I}_{\mathrm{d}} 5 \mathrm{~A} / \mathrm{div}$, time base $20 \mathrm{us} / \mathrm{div}$.

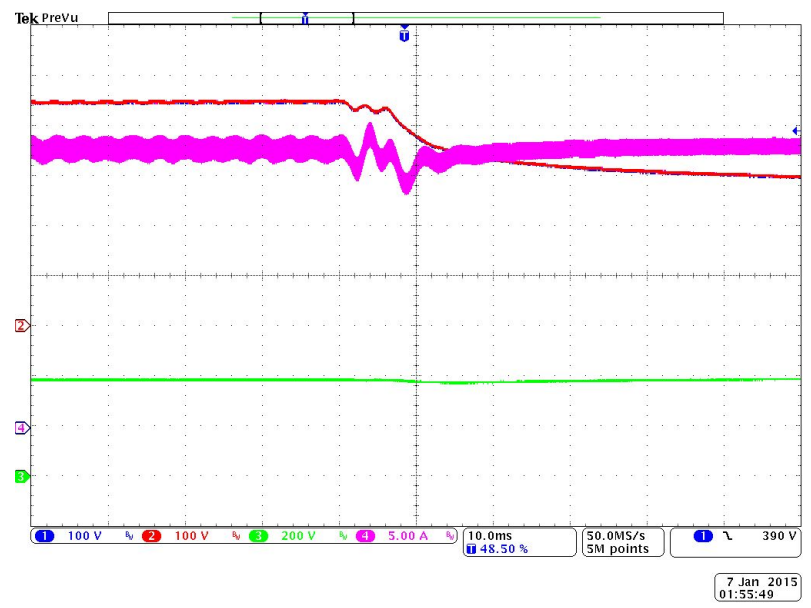

Fig. 13. Input voltage step change (Uin $=900 \mathrm{VDC}$ to Uin $=600 \mathrm{VDC}$, Pout $=10 \mathrm{~kW}), \quad$ Ch1 - Uc1 $100 \mathrm{~V} / \mathrm{div}, \quad$ Ch2 - Uc2 $100 \mathrm{~V} / \mathrm{div}, \quad$ Ch3 $\mathrm{u}_{\text {out }} 200 \mathrm{~V} / \mathrm{div}, \mathrm{Ch} 4$ - Id $5 \mathrm{~A} / \mathrm{div}$, time base $10 \mathrm{~ms} / \mathrm{div}$.

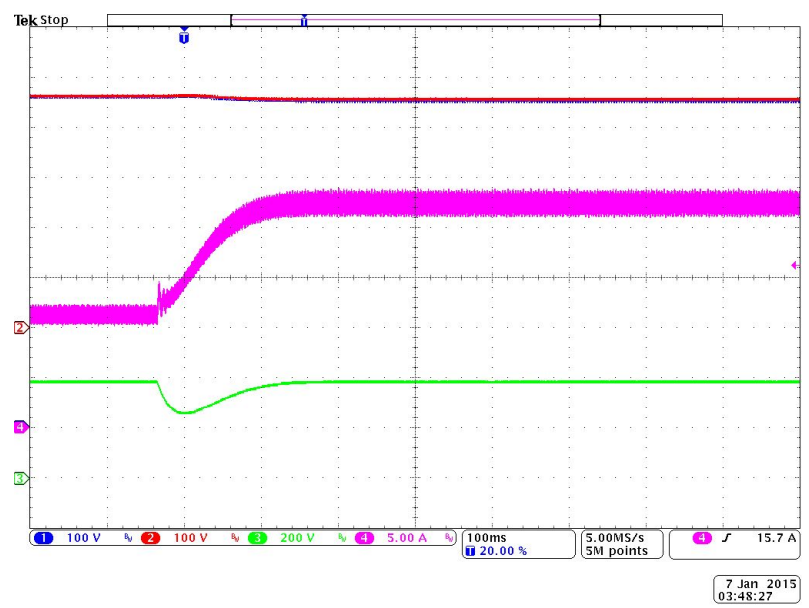

Fig. 14. Load step change (Pout $=5 \mathrm{~kW}$ to Pout $=10 \mathrm{~kW}$, $\mathrm{Uin}=600 \mathrm{VDC}), \quad \mathrm{Ch} 1-\mathrm{U}_{\mathrm{c} 1} 100 \mathrm{~V} / \mathrm{div}, \quad \mathrm{Ch} 2-\mathrm{U}_{\mathrm{c} 2} 100 \mathrm{~V} / \mathrm{div}, \quad \mathrm{Ch} 3-$ $\mathrm{u}_{\text {out }} 200 \mathrm{~V} / \mathrm{div}, \mathrm{Ch} 4-\mathrm{I}_{\mathrm{d}} 5 \mathrm{~A} / \mathrm{div}$, time base $100 \mathrm{~ms} / \mathrm{div}$.

Attention was also paid to the efficiency measurement as the losses may limit practical application due to unacceptable temperature rise of discrete semiconductor devices. Figure 15 illustrates the efficiency curve for the nominal voltage $U_{\text {in }}=750$ VDC. An efficiency of over $97 \%$ is kept within the output power range of $2 \mathrm{~kW}$ up to approximately $20 \mathrm{~kW}$.

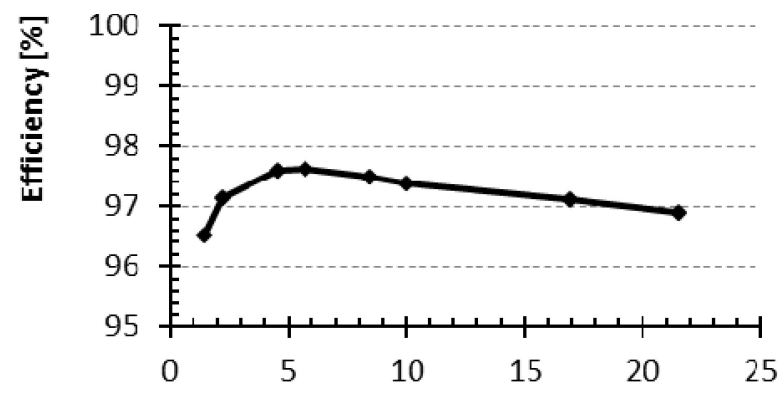

Output power $[\mathrm{kW}]$

Fig. 15. Overall converter efficiency for Uin $=750$ VDC.

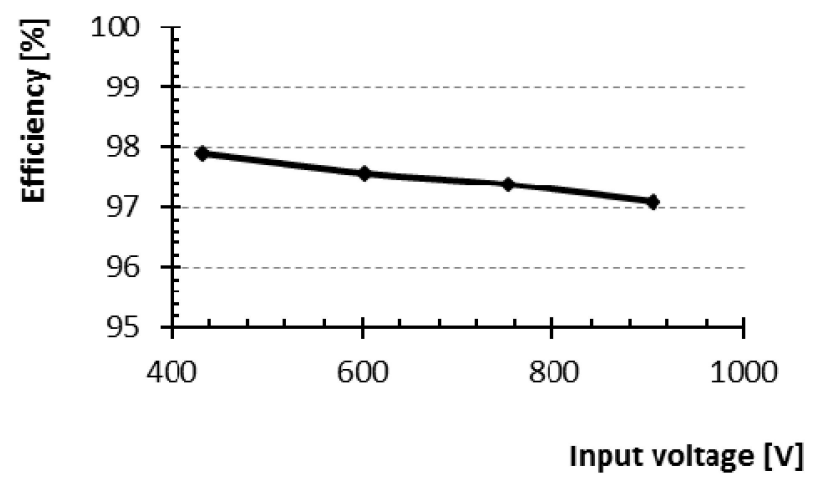

Fig. 16. Overall converter efficiency for various $U_{\text {in }}, P=10 \mathrm{~kW}$.

The influence of the input voltage on the efficiency is documented in Fig. 16, which also validates the proper function of the converter over the whole input voltage range. It confirms the domination of switching losses over conductive losses as the value decreases with increasing input voltage.

\section{CONCLUSIONS}

This work proposed prospective design concept of a hard switching input voltage stabilizer (IVS) for the auxiliary drive converters usable in dc catenary fed light traction vehicles.

Its main characteristics involve high switching frequency, good efficiency and reasonable cost due to the use of the latest generation $1200 \mathrm{~V}$ discrete semiconductor components.

The converter properties were experimentally verified on a full scale laboratory prototype. The results proved that employing the latest generation of semiconductor devices in a cost effective discrete package allows the design of an IVS converter with an output power of $22 \mathrm{~kW}$ that is capable of reliable operation within the whole range of catenary voltage fluctuation $400 \mathrm{VDC}-950 \mathrm{VDC}$. Achievable switching frequencies of up to $30 \mathrm{kHz}$ likewise promise better passive component optimization in comparison with concepts with $1700 \mathrm{~V}$ devices.

Since this proposal is topologically based on a serial combination of buck converters, even voltage distribution among each section is a key functionality. The presented experimental verification under a steady state, and mainly under various transients, proved that the converter is capable of very good performance. 
The overall efficiency of the laboratory prototype which varies between $97 \%$ and $98 \%$ under almost all input voltage and load conditions promises feasible design for industrial application.

Comparing the existing IVS concept $(1,7 \mathrm{kV}$ IGBT $+8 \mathrm{kHz})$ and new IVS concept $(1,2 \mathrm{kV}$ IGBT $+30 \mathrm{kHz})$ we can conclude that the new IVS concept reduces the price by of $13 \%$, the size by $7 \%$ and finally the weight by $15 \%$.

\section{REFERENCES}

[1] O. Deblecker, A. Moretti, F. Vallee, "Comparative study of softswitched isolated DC-DC converters for auxiliary railway supply", IEEE Trans. Power Electron., vol. 23, no. 5, pp. 2218-2229, 2008. [Online]. Available: http://dx.doi.org/10.1109/TPEL.2008.2001879

[2] B. Whitaker, A. Barkley, Z. Cole, B. Passmore, D. Martin, T. R. McNutt, A. B. Lostetter, J. S. Lee, K. Shiozaki, "A high-density, high-efficiency, isolated on-board vehicle battery charger utilizing silicon carbide power devices", IEEE Trans. Power Electron., vol. 29, no. 5, pp. 2606-2617, 2014. [Online]. Available: http://dx.doi.org/ 10.1109/TPEL.2013.2279950

[3] B. P. McGrath, D. G. Holmes, P. J. McGoldrick, A. D. McIver, "Design of a soft-switched 6-kW battery charger for traction applications", IEEE Trans. Power Electron., vol. 22, no. 4, pp. 11361144, 2007. [Online]. Available: http://dx.doi.org/10.1109/ TPEL.2007.900458

[4] G. Buja, "Light electric vehicles", Industrial and Information Systems, 2008. [Online]. Available: http://dx.doi.org/10.1109/ iciinfs.2008.4798325

[5] M. Shen, L. Diao, Y. Mei, Z. Li, Z. Liu, "Design and control of $100 \%$ low floor light rail vehicle traction system", IEEE Vehicle Power and Propulsion Conf., China, 2008. [Online]. Available: http://dx.doi.org/10.1109/vppc.2008.4677408

[6] R. Radvan, B. Dobrucky, M. Frivaldsky, "Modelling and design of
HF $200 \mathrm{kHz}$ transformers for hard- and soft-switching application", Elektronika Ir Elektrotechnika, vol. 4, pp. 7-12, 2011. [Online]. Available: http://dx.doi.org/10.5755/j01.eee.110.4.276

[7] I. Barbi, R. Gules, "Isolated DC-DC converters with high-output voltage for TWTA telecommunication satellite applications", IEEE Trans. Power Electron., vol. 18, no. 4, pp. 975-984, 2003. [Online]. Available: http://dx.doi.org/10.1109/TPEL.2003.813762

[8] D. Sha, Z. Guo, X. Liao, "Control strategy for input-parallel-outputparallel connected high-frequency isolated inverter modules", IEEE Trans. Power Electron., vol. 26, no. 8, pp. 2237-2248, 2011 [Online]. Available: http://dx.doi.org/10.1109/TPEL.2010.2095041

[9] H. Fan, H. Li, "High-frequency transformer isolated bidirectional DC-DC converter modules with high efficiency over wide load range for $20 \mathrm{kVA}$ solid-state transformer", IEEE Trans. Power Electron. vol. 26, no. 12, pp. 3599-3608, 2011. [Online]. Available: http://dx.doi.org/10.1109/TPEL.2011.2160652

[10] T. Labella, W. Yu, J.-S. Lai, M. Senesky, D. Anderson, "A bidirectional-switch-based wide-input range high-efficiency isolated resonant converter for photovoltaic applications", IEEE Trans. Power Electron., vol. 29, no. 7, pp. 3473-3484, 2014. [Online]. Available: http://dx.doi.org/10.1109/TPEL.2013.2282258

[11] N. Mohan, M. U. Tore, P. R. William, Power Electronics. Converters, Application and Design. New York: John Wiley \& Sons, 1995.

[12] Xinke Wu, Guichao Hua, Junming Zhang, Zhaoming Qian, "A new current-driven synchronous rectifier for series-parallel resonant (LLC) DC-DC converter", IEEE Trans. Industrial electronics, vol. 58, no. 1, pp. 289-297, 2011. [Online]. Available: http://dx.doi.org/10.1109/TIE.2010.2044129

[13] Ray-Lee Lin, Chiao-Wen Lin, "Design criteria for resonant tank of LLC DC-DC resonant converter", IECON, Phoenix, AZ, 2010, pp. $427-432$

[14] J. Jordan, V. Esteve, E. S.-Kilders, E. J. Dede, E. Maset, J. B. Ejea, A. Ferreres, "A comparative performance study of a $1200 \mathrm{~V} \mathrm{Si}$ and $\mathrm{SiC}$ MOSFET intrinsic diode on an induction heating inverter", IEEE Trans. Power Electron., vol. 29, no. 5, pp. 2550-2562, 2014. [Online]. Available: http://dx.doi.org/10.1109/TPEL.2013.2282658 